\title{
COMERCIALIZAÇÃO NO AGRONEGÓCIO: UM ESTUDO SOBRE ASSENTAMENTOS DA REFORMA AGRÁRIA NO CONTEXTO DA ECONOMIA SOLIDÁRIA
}

\author{
Bruno Diego Alcantara Cardozo* \\ Gabriel Sgrignoli Mello** \\ Milton Augusto Pasquotto Mariani**** \\ Élcio Gustavo Benini***** \\ Geraldino Carneiro de Araújo ***:*
}

RESUMO: Este artigo analisa a comercialização em assentamentos da reforma agrária no contexto da economia solidária. Trata-se de uma pesquisa exploratória, descritiva e de natureza quantitativa. Para a análise foi utilizada a estatística descritiva com base na versão 2010-2012 do Sistema Nacional de Informações de Economia Solidária (SIES), que possui informações válidas de 1.033 empreendimentos econômicos solidários (EES) que indicaram como categoria social assentamento da reforma agrária, representando $5,24 \%$ do total de respondentes. Os resultados mostram que (a) a maior parte dos EES está localizada na região Nordeste do Brasil, (b) a principal atividade econômica é a produção ou produção e comercialização, (c) grande parte dos assentamentos não participa de redes de comercialização, (d) a principal destinação dos produtos é a venda e o autoconsumo, (e) os mercados consumidores em destaque são o mercado/comércio municipal e o mercado/comércio local ou comunitário, e (f) ambas variáveis se alinham à ideia de fortalecimento do próprio grupo de assentados, incluindo a inserção de produtos no contexto do agronegócio e a promoção de bem-estar dos trabalhadores, reforçando os valores e desígnios da

\footnotetext{
Mestre em Administração pela Escola de Administração e Negócios da Universidade Federal de Mato Grosso do Sul (ESAN/UFMS), Brasil. E-mail: brunodiegocardozo@gmail.com

** Mestre em Administração pela Escola de Administração e Negócios da Universidade Federal de Mato Grosso do Sul (ESAN/UFMS), Brasil.

*** Pós-doutor em Administração pela Universidade de São Paulo (USP). Docente permanente no Programa de Pós-graduação em Administração (PPGAD) da Escola de Administração e Negócios da Universidade Federal de Mato Grosso do Sul (ESAN/UFMS), Brasil.

**** Doutor em Educação pela Universidade Federal de Mato Grosso do Sul (UFMS). Docente permanente no Programa de Pós-graduação em Administração (PPGAD) e no Mestrado Profissional em Administração Pública em Rede Nacional (PROFIAP) na Escola de Administração e Negócios da Universidade Federal de Mato Grosso do Sul (ESAN/UFMS), Brasil.

***** Doutor em Administração pela Universidade Nove de Julho (UNINOVE). Docente permanente no curso de Administração da Universidade Federal de Mato Grosso do Sul Câmpus de Paranaíba (CPAR/UFMS) e no Mestrado Profissional em Administração Pública em Rede Nacional (PROFIAP) da Escola de Administração e Negócios da Universidade Federal de Mato Grosso do Sul (ESAN/UFMS), Brasil.
} 
reforma agrária.

PALAVRAS-CHAVE: Assentamentos; Comercialização; Reforma agrária.

\section{TRADING IN AGRIBUSINESS: A STUDY ON AGRARIAN REFORM SETTLEMENTS WITHIN THE CONTEXT OF SOLIDARY ECONOMY}

ABSTRACT: Trade in agrarian reform settlements within the context of solidary economy is discussed. Current exploratory, descriptive and quantitative research comprises descriptive statistics based on the 2010-2012 version of the National System of Information of Solidary Economy (SIES) with valid information of 1033 solidary economic enterprises (EES) which indicated as social category the agrarian reform settlement, with $5.24 \%$ of total respondents. Results show that (a) most EES lie in the northeastern region of Brazil; (b) main economic activity is production or production plus commercialization; (c) most settlements fail to participate in commercialization networks; (d) the main target is selling and self-consumption; (e) underscored consumer markets are market/town trade and market/local or community trade; (f) both variables align to strengthen settler groups including the insertion of products within the agribusiness context and the promotion of the workers' life style, with a reinforcement of values and designs of agrarian reform.

KEY WORDS: Settlements; Trade; Agrarian reform.

\section{INTRODUÇÃO}

O agronegócio, na pioneira perspectiva de abordagem sistêmica de Davis e Goldberg (1957), foi conceituado como a soma de todas as operações envolvidas no processo de produção e distribuição dos insumos agropecuários, tais como: armazenamento, processamento e a distribuição dos produtos agrícolas e seus derivados. Essa definição foi crucial para o desenvolvimento de várias outras para explicar a crescente inter-relação setorial entre agricultura, indústria e serviços, sendo as principais abordagens: commodity system approach - CSA, discutido por Goldberg (1968); filièri, em que seu conceito foi concretizado por Montiguad (1992); cadeia produtiva, que é uma abordagem derivada da escola francesa e é discutida por Batalha (2001); outra abordagem é o sistema agroindustrial - SAG, no qual é discutido 
por Castro (2001); e também a abordagem da supply chain management - SCM, discutida por Ching (1999).

Face às mazelas sociais e à difícil concorrência e processos de concentração produtiva e de riquezas, realidades encontradas e reproduzidas nas estruturas fundiárias e no mundo do agronegócio que, conforme enfatizaram Davis e Goldberg (1957), precisam ser realmente observadas sistematicamente.

Além disso, a partir das considerações das contradições que a totalidade do metabolismo social hegemônico reproduz é possível observar, tanto em âmbito prático-concreto como a nível teórico, formas alternativas de produção, comercialização e distribuição. Entre as alternativas e experiências socioprodutivas encontra-se a economia solidária (BENINI; BENINI; 2008).

A economia solidária pode ser entendida como uma alternativa que busca a produção de produtos e serviços, muitas vezes com enfoque agrícola, e promover a geração de trabalho, renda e inserção social. A economia solidária é fundamentada nos preceitos de cooperativismo, igualdade, transparência, democracia e autogestão (SINGER, 2002). A reforma agrária e os assentamentos rurais, quando organizados de forma a promover a cooperação e solidariedade, assemelham-se ao modelo econômico solidário, visando garantir o labor para todos os rurais sem-terra, garantir o bem-estar social e a melhoria das condições de vida de maneira igualitária para todos, além de buscar permanentemente a justiça social.

Conforme dados do Programa Nacional de Reforma Agrária (PNRA, 2015), sob a jurisdição e atuação das Superintendências Regionais do INCRA, existem 1.346.798 assentamentos de trabalhadores rurais entre 1994 e 2015, sendo 26.335 estabelecidos em 2015 (INCRA, 2016). Além disso, de acordo com Costa, Amorim Junior e Silva (2015) e Silva, Dias e Amorim Junior (2015), muitas das dificuldades que se passam após o processo de distribuição das terras diz respeito à sustentação da produção e comercialização da produção dos assentados. Ressalta-se que a competição no âmbito rural abriga estruturas de mercado que favorecem economias de escala e escopo e, portanto, tornam difícil a vida no campo. É diante dessas dificuldades que a cooperação na produção e comercialização apresenta-se como uma estratégia de desenvolvimento econômico e manutenção das famílias e produtores rurais. Diante dessa contextualização, emerge a seguinte questão de pesquisa: Quais são as características da comercialização em assentamentos da reforma agrária? A 
cooperação e a perspectiva de solidariedade têm proporcionado bem-estar aos assentados?

Diante do exposto, neste artigo buscou-se analisar a comercialização em assentamentos da reforma agrária tendo como campo empírico de investigação a base de dados do Sistema Nacional de Informações de Economia Solidária (SIES). Considerou-se como características da comercialização o período entre 2010 e 2013: redes, destino dos produtos, tipo de venda, mercado comprador, espaço de comercialização, forma de organização da comercialização, produtos comercializados, forma de comercialização, mercado e dificuldades na comercialização dos produtos.

Nessa primeira seção foram apresentados os aspectos introdutórios do texto. No tópico seguinte estão os aspectos teóricos quanto à comercialização em assentamentos rurais. Os procedimentos metodológicos são expostos no item três. $\mathrm{Na}$ seção quatro são apresentados os resultados e análise dos dados considerando a caracterização da amostra, redes e comercialização nos assentamentos da reforma agrária. No tópico cinco as considerações finais e, por fim, as referências do texto.

\section{ASPECTOS TEÓRICOS QUANTO À COMERCIALIZAÇÃO EM ASSENTAMENTOS RURAIS}

A expansão das relações capitalistas no campo impulsionou o processo de expropriação/expulsão dos trabalhadores rurais. A partir do final da década de 1970, com o surgimento do Movimento dos Trabalhadores Rurais Sem-Terra (MST), os trabalhadores passaram a se organizar e promover ações de luta para conquista da terra. A conquista da terra e o desenvolvimento econômico não significam apenas a inclusão do sem-terra no mundo produtivo, mas a conquista de direitos, consciência política e cidadania (FABRINI, 2001). Esterci et al. (1992) referem o termo assentamento às ações que buscam ordenar ou reordenar recursos fundiários com alocações de populações para solução de problemas socioeconômicos. As ações do Estado são, portanto, concebidas como de ordem técnica e não tão somente política, por outro lado, os beneficiários estão destituídos de caráter ativo.

O MST, fomentado pela Confederação das Cooperativas de Reforma Agrária 
do Brasil (CONCRAB), defende a necessidade da implantação de cooperativas agrícolas nos assentamentos como uma das maneiras para fortalecer a luta pela transformação da sociedade. Cooperativas não devem se organizar somente com objetivos econômicos, mas também com desígnios políticos em longo prazo, capazes de promover conscientização dos trabalhadores para o fortalecimento de suas lutas em prol do desenvolvimento social. As consequências e a estima das cooperativas residem na capacidade de mobilização de trabalhadores em prol do alcance dos objetivos relacionados à produção e à luta pela terra e a liberação de membros das cooperativas para atuar na luta pela reforma agrária (FABRINI, 2001).

O termo assentamento rural, no âmbito das políticas públicas para nomear um tipo de intervenção fundiária, unifica e, por vezes, encobre compras de terras, desapropriação de imóveis rurais ou utilização de terras públicas. Os assentamentos tendem a fortalecer os movimentos de luta pela terra, pois se constituem como prova da eficácia de pressões intensas, especialmente em ocupações de terra e acampamentos; provocam rearranjos institucionais, suscitando na necessidade de um aparelhamento de Estado para lidar com a criação de novos organismos ou reformulação dos existentes nos governos federais, estaduais e municipais, além de regulamentação e novas leis; possibilitam a geração de empregos e aumento do nível de renda de boa parte das famílias assentadas, com enfoques nas economias municipais e regionais; possui potencial para alterar as relações de poder local, em menor ou maior medida (MEDEIROS; LEITE, 2004).

Existe o reconhecimento dos assentados em torno da produção e dimensão econômica articulada à dimensão política. Desta perspectiva emerge uma das principais propostas de produção dos assentados, já que a organização da produção e a manutenção na terra enquanto trabalhadores rurais assentados são tomadas por sua própria capacidade de organização e mobilização política. Por acreditarem na importância da dimensão política na organização da produção agrícola no interior dos assentamentos, os sem-terra passaram a desenvolver ações como a organização de trabalhos associativos/cooperativos/coletivos. Entretanto, não se limitam apenas a uma organização artesanal e associações semelhantes às "roças comunitárias". A operação agrícola dos sem-terra, em sua concepção, é semelhante a um empreendimento que apresenta inserção mercantil, regras e códigos formais. Os camponeses sem-terra concebem a organização associativa como uma saída para a sua manuten- 
ção no campo (FABRINI, 2001).

A reforma agrária é uma solução não apenas para os problemas do meio rural, mas de toda a sociedade brasileira e do meio urbano. A reforma agrária, conceituada por Stedile (2005, p. 188), tem os seguintes objetivos:

a) garantir o trabalho para todos os trabalhadores rurais Sem Terra, combinando distribuição de renda e desenvolvimento cultural; b) produzir alimentação farta, barata e de qualidade a toda população brasileira, especialmente a urbana em prol de segurança alimentar para a sociedade; c) garantir o bem-estar social e a melhoria das condições de vida de maneira igualitária para todos os brasileiros, em especial aos trabalhadores e prioritariamente aos pobres; d) buscar permanentemente a justiça social, a igualdade de direitos em todos os aspectos: econômico, político, social, cultural e espiritual; e) difundir a prática de valores humanistas e socialistas nas relações entre indivíduos, eliminando-se as práticas de discriminação racial, religiosa e de gênero; f) contribuir para criar condições objetivas de participação igualitária da mulher na sociedade, garantindo-lhes direitos iguais; g) preservar os recursos naturais, como águas, solos, florestas, entre outros, em prol de desenvolvimento sustentável; h) implementar a agroindústria e a indústria como principal meio de se desenvolver o interior do país; i) gerar emprego para todos que queiram trabalhar na terra.

Existe nos assentamentos a preocupação primeira de garantir a manutenção e reprodução do assentado. O objetivo é a garantia de sobrevivência por meio da organização da produção no interior dos assentamentos. Para isso, a produção agrícola torna-se o principal centro de discussões, pois o sem-terra assentado quer terra porque, dessa maneira, consegue garantir as necessidades básicas de sua família, portanto, busca-se o lucro pela vida e não para o lucro. Muito além de pensar na produção para o mercado, os sem-terra assentados concebem a organização produtiva para a vida. Por meio de trabalho organizado em lotes individualmente ou coletivamente, os sem-terra colocam na prática as experiências adquiridas, não somente na agricultura, mas experiências de luta pela terra, onde se destaca o aspecto da dimensão política, implícita na organização da produção agrícola no assentamento. O mercado, por sua vez, não é reconhecido como um mecanismo para a garantia de sua permanência na terra, uma vez que os segmentos dominantes da sociedade (capital mercantil, industrial, financeiro) subtraem os benefícios resultantes do trabalho e renda. A lógica, por conseguinte, não prioriza o trabalho e, dessa maneira, 
elaboram-se propostas de organização da produção para subverter a ordem desigual da economia de mercado e do modo de produção capitalista (FABRINI, 2001).

Na prática a reforma agrária proporciona:

1) desconcentração e democratização da estrutura fundiária; 2) produção de alimentos básicos; 3) geração de ocupação e renda; 4) combate à fome e à miséria; 5) interiorização dos serviços públicos básicos; 6) redução da migração campo-cidade; 7) promoção da cidadania e da justiça social; 8) diversificação do comércio e dos serviços no meio rural; 9) democratização das estruturas de poder (INCRA, 2017).

No contexto de assentamentos da reforma agrária é possível agregar um arranjo que fomenta o desenvolvimento da própria categoria social. As redes solidárias buscam gerar trabalho e renda para as pessoas desempregadas e marginalizadas, ou que desejam construir novas relações de produção, melhorar o padrão de consumo dos participantes e proteger o meio ambiente, construindo assim uma nova sociedade sem exploração das pessoas ou degradação do equilíbrio ecológico. Parte do excedente obtido pelos produtores e prestadores de serviços na rede é reinvestida na própria rede para gerar mais cooperativas, grupos de produção e microempresas, a fim de criar novos postos de trabalho e aumentar a oferta solidária de produtos e serviços. Essa dinâmica permite incrementar o consumo de todos, além de diminuir o volume e o número de itens que a rede ainda compra do mercado, evitando o acúmulo de riqueza do sistema capitalista. A rede busca, portanto, produzir tudo o que as pessoas necessitam para realizar o bem-viver de cada um, ecologicamente e socialmente sustentável (MENDES, 2003).

A comercialização é, para diversos produtos provenientes da agricultura familiar, um importante gargalo para o crescimento da renda e especialmente para a sua estabilidade, o que é crucial para a sustentabilidade das famílias na atividade agropecuária. Os problemas relacionados à comercialização foram profundamente alterados nos últimos 15 anos, tornando essa atividade particularmente importante para os sistemas de produção cuja principal fonte de conhecimento é a tradição, como é o caso da agricultura familiar. Na produção familiar, o conhecimento sobre técnicas de produção e práticas de comercialização tende a ser transmitido dentro da família, sendo, portanto, fortemente ligado às práticas tradicionais (AZEVEDO; 
FAULIN, 2009). Conforme os autores, em um ambiente de menor proteção, o setor produtivo, algumas vezes induzido por instrumentos de política agrícola, desenvolveu diversos mecanismos de comercialização que procuravam lidar com a nova realidade de: a) maior risco de preços; b) menor disponibilidade de crédito em condições compatíveis com a atividade rural; e, c) maiores oportunidades de diferenciação de produto.

Os mecanismos de comercialização comumente adotados por produtores familiares, em sua relação com os agentes do canal de distribuição, são: spot, contrato formal, contrato informal e parceria. A comercialização em via spot é utilizada para coordenar as transações entre produtores familiares e sacolões, varejões, quitandas, atravessadoras, entre outros, que normalmente são outros produtores familiares ou patronais, além da venda direta para o consumidor final. O contrato informal com base na confiança usualmente é o mais utilizado pelos produtores familiares na venda de seus produtos por conta da capacidade de atender ao mercado com maior regularidade, permitindo firmar compromissos por prazos mais longos. A parceria, por sua vez, é motivada, por um lado, por produtores que desejam expandir sua participação no mercado, mas não dispõem de recursos financeiros suficientes ou interesse para investir no aumento da produção; e, por outro lado, por produtores que desejam iniciar determinada atividade agrícola, mas não possuem o conhecimento técnico necessário ou encontram dificuldades para ingressar no mercado. Nesse sentido, por meio da parceria, o produtor familiar encontra condições de iniciar a atividade econômica atuando como fornecedor de produtos agrícolas aos primeiros, os quais, além de produtores, passam a desempenhar a função de atravessadores (MENDES, 2003).

Ainda sobre os mecanismos de comercialização, a escolha de produtos agropecuários é realizada com referência em suas principais funções: a) transferência física do produto; b) gerenciamento de risco; c) financiamento; d) indução de ações de coordenação da cadeia; e) e, transmissão de informações. O exame de cada uma dessas funções define a escolha do mecanismo de comercialização (AZEVEDO; FAULIN, 2009). As principais funções a que um mecanismo de comercialização deve atender são definidas pelas características do agricultor familiar. Essas funções possibilitam identificar qual é a alternativa mais interessante para o produtor familiar. 
Em face às dificuldades apresentadas é que a economia solidária apresenta-se como uma alternativa de geração de trabalho, renda e inclusão social para os assentados. Não obstante não seja objetivo deste artigo lançar mão sobre uma discussão teórica sobre economia solidária - uma vez que existem várias abordagens teóricas -, o conceito síntese norteador desta pesquisa é aquele apresentado por Gaiger (2003), para o qual a economia solidária é uma espécie de cooperação econômica que visa alcançar a autogestão, havendo uma unidade em relação à posse $\mathrm{e}$ o uso dos meios de produção.

\section{PROCEDIMENTOS METODOLÓGICOS}

A pesquisa se caracteriza como exploratória, descritiva e quantitativa. A pesquisa exploratória busca examinar de uma maneira mais clara as propriedades definidas pelo pesquisador (COOPER; SCHINDLER, 2011). De acordo com Collis e Hussey (2005), a pesquisa descritiva envolve a descrição de processos, bem como fenômenos ou problemáticas. A pesquisa é quantitativa com investigação conduzida por meio de planejamento estabelecido e com variáveis já definidas, com o intuito de mediar e quantificar os resultados (GODOY; 1995). A pesquisa quantitativa preza por precisão e evita possíveis distorções de dados, controlando os sentidos intuitivos e a imaginação, e, sobretudo, reduzindo a subjetividade por meio dos caminhos delimitados da pesquisa (MARTINS, 2004).

Os dados foram coletados a partir da base de dados do Sistema Nacional de Informações em Economia Solidária (SIES), desenvolvido pela Secretaria Nacional de Economia Solidária sob a coordenação da Comissão Gestora Nacional e em parceria com o Fórum Brasileiro de Economia Solidária enquanto um instrumento para identificação e registro de informações de empreendimentos econômicos solidários, entidades de apoio e fomento à economia solidária e políticas públicas de economia solidária no Brasil.

A intenção do instrumento envolve a identificação e registro de informações dos empreendimentos econômicos solidários, entidades de fomento e apoio à economia solidária e políticas públicas de economia solidária no Brasil. Utilizou-se a versão 2010-2012, que conta com informações válidas de 19.708 empreendimentos 
econômicos solidários, destes 1.033 empreendimentos indicaram como categoria social assentamento da reforma agrária, aproximadamente representam 5,24\% do total de respondentes.

Optou-se pelo enfoque em assentamentos da reforma agrária, pois, conforme o Estatuto da Terra - Lei no 4504/1964, a reforma agrária é o conjunto de medidas para promover a melhor distribuição da terra mediante modificações no regime de posse e uso, a fim de atender aos princípios de justiça social, desenvolvimento rural sustentável e aumento de produção (BRASIL, 1964). Além disso, os dados da SIES afirmam a fragilidade desse objeto e carência de estudos científicos voltados a essa característica social de assentamentos de reforma agrária.

As dimensões e variáveis abordadas na pesquisa foram:

I) Caracterização da amostra: região do país; forma de organização; número de mulheres sócias; número de homens sócios; área de atuação do empreendimento; faturamento mensal do empreendimento (valor médio mensal); e, atividade econômica;

II) Comercialização:

a) Participação em redes;

b) Produção ou produção e comercialização: destino dos produtos, tipo de venda, mercado comprador, espaço de comercialização e dificuldades de comercialização;

c) Comercialização ou organização da comercialização: forma de organização da comercialização, forma de comercialização, mercado e dificuldades na comercialização dos produtos.

O item I apresenta uma caracterização da amostra e o item II está dividido em três partes. A primeira apresenta uma análise do quantitativo de assentados sobre a participação em diversas redes. A segunda considera os empreendimentos que responderam que desenvolvem atividades econômicas de produção ou comercialização. E a terceira parte considera os empreendimentos que responderam que desenvolvem atividades de comercialização e organização da comercialização. Optou-se pela estatística descritiva como tratamento de dados tendo como objetivo 
inicial de descrever e sumarizar o grande conjunto de dados da base SIES.

\section{RESULTADOS E DISCUSSÃO}

Os dados analisados foram coletados na base de dados do Sistema Nacional de Informações de Economia Solidária (SIES), na versão 2010-2012, que reúne informações de 19.708 Empreendimentos Econômicos Solidários (EES). Desses, 1.033 empreendimentos indicaram como categoria social "assentados da reforma agrária", representando 5,24\% do total de respondentes.

\subsection{CARACTERIZAÇÃO DA AMOSTRA}

Os EES, que enquadrados na categoria social assentados da reforma agrária encontram-se em todas as regiões no Brasil, no entanto, estão concentrados em maior parte, na região Nordeste (36,98\%). A região Centro-Oeste $(27,49 \%)$ é a segunda com maior porcentagem de assentamentos, seguida pelo Norte $(14,33 \%)$, Sudeste $(12,68 \%)$ e Sul $(8,52 \%)$ do país. Dados oficiais da pesquisa denotam que a maioria dos EES formados por assentados organizam-se em forma de associação $(72,99 \%)$.

Além disso, reúnem-se em grupos informais (17,23\%) e cooperativas $(9,47 \%)$. O contexto dos assentamentos de reforma agrária, incluindo suas peculiaridades no processo de produção e comercialização de seus produtos, enfrenta grandes dificuldades quanto à sua base estrutural, seus recursos produtivos e, ainda, em relação à sua própria inserção no mercado institucionalizado, por questões burocráticas e políticas que possam dificultar sua inclusão. A própria impossibilidade de emissão de nota fiscal pelas associações já é um fator determinante para sua entrada em mercados institucionais.

O gênero masculino (62,08\%) sobressai em relação ao feminino $(37,92 \%)$. Os assentamentos de reforma agrária geralmente atuam na área rural (90,22\%). Uma pequena parcela, contudo, atua na área rural e urbana (7,55\%). Em relação ao faturamento existem $95 \mathrm{EES}(17,33 \%)$ que faturam entre $\mathrm{R} \$ 16.000,00$ até $\mathrm{R} \$ 50.000,00$ e 63 empreendimentos (11,50\%) que faturam de $R \$ 50.000,00$ até $R \$ 100.000,00$. A 
questão faturamento foi abordada apenas em relação à atividade econômica voltada à produção ou produção e comercialização, em que, em um total de 549 empreendimentos, apenas um não respondeu essa questão.

Considerando que a comercialização é o enfoque dessa pesquisa, apresentam-se as atividades econômicas realizadas pelos assentados da reforma agrária. Destacam-se "Produção ou produção e comercialização" (53,15\%) e "Comercialização ou organização da comercialização" (16,65\%), que juntas representam 69,8\% das atividades dos respondentes. A seguir são apresentados os dados e discussões sobre: a) redes; b) produção ou produção e comercialização; e, c) comercialização ou organização da comercialização.

\subsection{COMERCIALIZAÇÃO NOS ASSENTAMENTOS DA REFORMA AGRÁRIA}

Neste tópico são apresentadas informações em relação à comercialização em redes feitas pelos EES cuja característica social é assentamentos da reforma agrária, além de informações sobre a comercialização dos EES em relação à sua atividade econômica, no caso produção ou produção e comercialização e também comercialização ou organização da comercialização, ressaltando a comercialização como uma característica importante do segmento assentamento rural.

\subsubsection{Redes}

Uma das maneiras de organização que impulsionam o desenvolvimento de grupos e empreendimentos que compartilham interesse comum é a participação em rede (FABRINI, 2001; MENDES, 2003; MEDEIROS; LEITE, 2004; STEDILE, 2005). Há uma série de preceitos, procedimentos e condutas para o alcance pleno do trabalho em rede, demandando maturidade de seus membros e coordenação em seus processos (MENDES, 2003). Observou-se, contudo, que a maior parte dos assentamentos agrários não participa de redes de comercialização $(85,58 \%)$, reforçando, dessa maneira, os desafios desse arranjo organizacional.

Os EES com categoria social assentamentos de reforma agrária que participam em redes encontram-se predominantemente em rede de comercialização 
(44,30\%) e, em seguida, em rede de produção (26,85\%). A participação em redes é, sobretudo, uma excelente maneira de estreitar laços com parceiros e, a partir dos acordos efetivados e ações realizadas em conjunto, aumentar a redução de custos em processos, insumos e produtos, principalmente relacionados à comercialização e produção (MENDES, 2003). Embora as proporções sejam menores, notou-se uma paridade de participação em redes em relação à cooperativa central $(11,41 \%)$, central de comercialização $(10,74 \%)$ e rede de crédito ou finanças solidárias $(10,74 \%)$.

\subsubsection{Produção ou Produção e Comercialização}

Dados da pesquisa do SIES confirmam que 549 EES $(53,15 \%)$ de assentamentos da reforma agrária desenvolvem atividades de produção ou produção e comercialização. Muito além de tão somente desenvolver produtos e/ou serviços, os assentamentos agrários precisam assegurar-se que seus produtos sejam distribuídos. Nessa perspectiva, a principal destinação é a venda (96,53\%) e o autoconsumo $(59,67 \%)$, uma vez que por meio dessas atividades os assentamentos agrários podem aumentar seu excedente produtivo e redistribui-lo em formas de investimentos para a melhoria de seus processos produtivos e, até mesmo, investir no desenvolvimento de novos produtos e serviços, fomentando a qualidade de vida dos membros de sua comunidade e fortalecendo o seu posicionamento no mercado já consolidado.

Por outro lado, ressalta-se também a produção para o autoconsumo, pois, embora isso justifique muitas vezes o baixo faturamento, ainda é elemento fundamental para o bem-estar de todos os membros dos assentamentos. Os tipos de venda dos EES são expostos na Figura 1. 


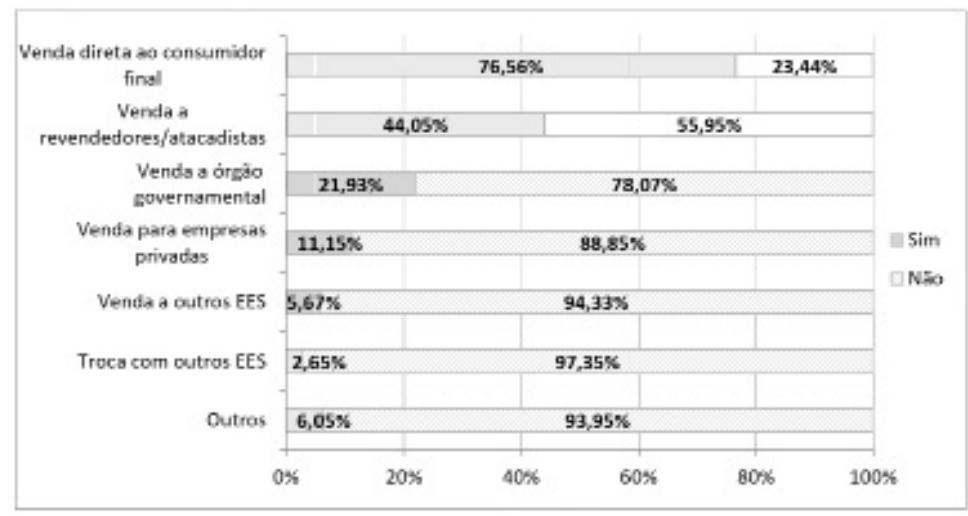

Figura 1. Tipo de venda.

Fonte: Elaborado pelos autores com base nos dados do SIES (2010-2012).

Identificou-se na Figura 1 que os EES de assentamentos agrários realizam venda direta ao consumidor final (76,56\%), reforçando o interesse de fortalecimento e escala de produção, manutenção de parcerias formais ou não formais e, ainda, prezando pela não intervenção de agentes fora de sua cadeia. Além disso, as vendas também são realizadas para revendedores/atacadistas (44,05\%), dessa maneira, é possível distribuir produtos no mercado competitivo enquanto assegura-se uma alternativa de geração de excedente e investimentos (AZEVEDO; FAULIN, 2009). Conforme pode ser observado ainda na figura em tela, existe um grande espaço para expansão da venda para órgãos governamentais. A priori, uma das razões disso, por estar realinhado com a forma de organização dos assentados, que 17,23\% ainda são maioria grupos informais e associações.

A seguir, na Figura 2, é apresentado o mercado consumidor dos EES. 


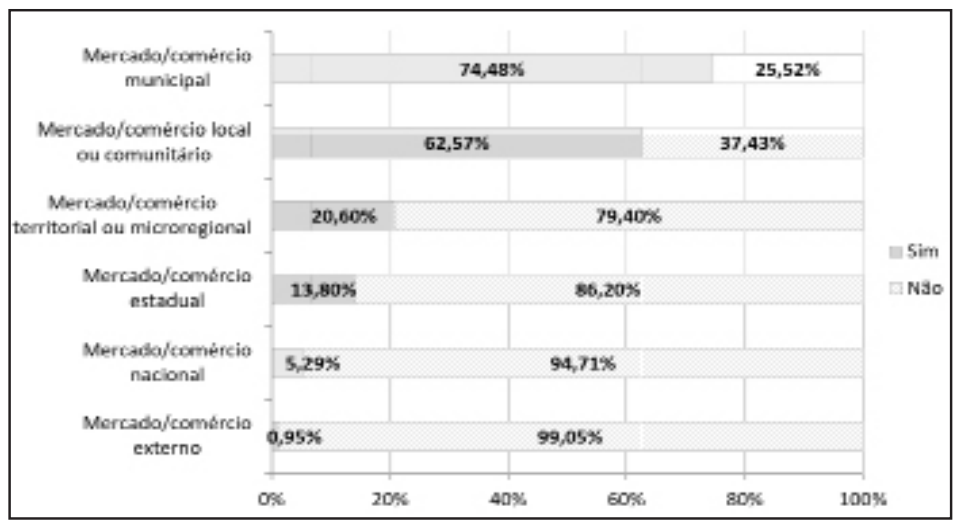

Figura 2. Mercado consumidor.

Fonte: Elaborado pelos autores com base nos dados do SIES (2010-2012).

Identificou-se na Figura 2 que os mercados consumidores em destaque são o mercado/comércio municipal $(74,48 \%)$ e o mercado/comércio local ou comunitário $(62,57 \%)$. Esses mercados reforçam o enfoque na promoção da economia local e comunitária, gerando benefícios para os EES de assentamentos agrários e seus respectivos membros. Assim como uma perspectiva de desenvolvimento endógeno e, considerando a soma do capital físico com o capital humano, progresso técnico e aquisição de conhecimento, é importante ressaltar que uma vez que a riqueza é produzida, esta, ao partir da localidade, tende a circular também na localidade e gerar benefícios a nível local e para seus membros, incluindo para o desenvolvimento econômico.

Os espaços de comercialização são apresentados na Figura 3. 


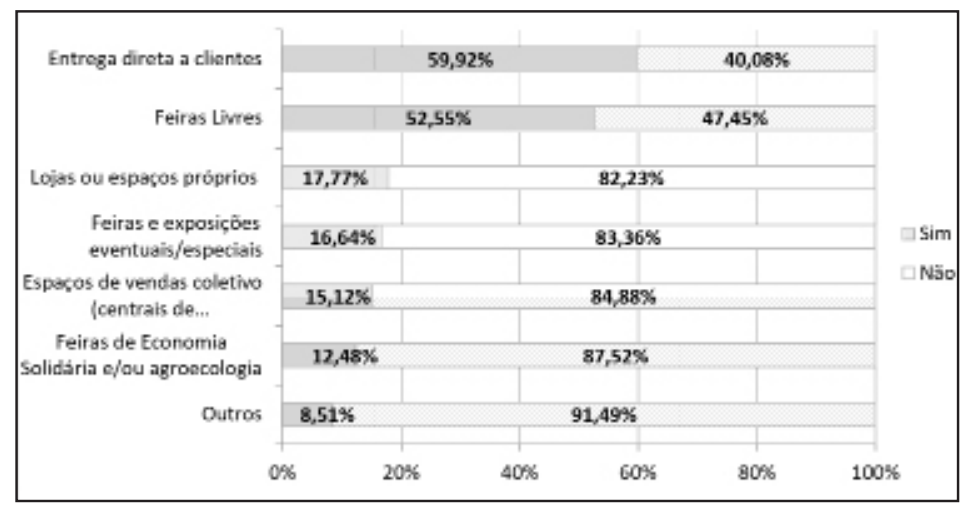

Figura 3: Espaço de comercialização.

Fonte: Elaborado pelos autores com base nos dados do SIES (2010-2012).

Em relação aos espaços de comercialização destacaram-se entrega direta a clientes (59,92\%) e feiras livres (52,55\%) (Figura 3). A escolha desses espaços geralmente se dá por questões de abertura, inserção e acesso público, embora por muitas vezes os produtores tenham interesse em fazer parte de outros canais de comercialização, incluindo o mercado institucionalizado (MENDES, 2003; AZEVEDO; FAULIN, 2009).

A pesquisa demonstrou que $67,67 \%$ dos EES em assentamentos agrários possuem dificuldades na comercialização de produtos e/ou serviços. Essa característica usualmente ocorre devido às relações de confiança entre parceiros e nível de colaboração e de negociação de produtos e serviços no sistema de assentamentos agrários que, por sua vez, possuem peculiaridades em suas próprias políticas e valores. Na Tabela 1 são apresentadas as dificuldades da comercialização apontadas pelos assentados. 
Tabela 1. Dificuldades encontradas na comercialização de produtos e/ou serviços

\begin{tabular}{|c|c|c|}
\hline Dificuldades & Frequência & $\%$ \\
\hline Falta de capital de giro & 209 & $58,38 \%$ \\
\hline Dificuldade ou custo elevado de transporte & 182 & $50,84 \%$ \\
\hline Precariedade das estradas para escoamento da produção & 154 & $43,02 \%$ \\
\hline $\begin{array}{l}\text { Estrutura para comercialização (local, espaço, equipamentos etc.) ina- } \\
\text { dequada }\end{array}$ & 137 & $38,27 \%$ \\
\hline A concorrência, os atravessadores, existência de monopólios & 132 & $36,87 \%$ \\
\hline Os preços praticados são inadequados & 132 & $36,87 \%$ \\
\hline Dificuldade em manter a regularidade do fornecimento & 122 & $34,08 \%$ \\
\hline Falta de registro legal para a comercialização (emitir nota fiscal etc.) & 92 & $25,70 \%$ \\
\hline Falta de registro sanitário ou alvará & 73 & $20,39 \%$ \\
\hline Os clientes exigem um prazo para o pagamento & 59 & $16,48 \%$ \\
\hline $\begin{array}{l}\text { O empreendimento tentou, mas não conseguiu encontrar quantidade } \\
\text { suficiente de clientes }\end{array}$ & 69 & $19,27 \%$ \\
\hline Não há sócios disponíveis para cuidar da comercialização & 57 & $15,92 \%$ \\
\hline O empreendimento já sofreu muitos calotes e não sabe como evitar & 41 & $11,45 \%$ \\
\hline Os compradores só compram em grande quantidade & 38 & $10,61 \%$ \\
\hline Os produtos não são conhecidos & 33 & $9,22 \%$ \\
\hline $\begin{array}{l}\text { Ninguém do empreendimento sabe como se faz uma venda (argumen- } \\
\text { tação, negociação etc.) }\end{array}$ & 19 & $5,31 \%$ \\
\hline Outra dificuldade & 41 & $11,45 \%$ \\
\hline
\end{tabular}

Fonte: Elaborado pelos autores com base nos dados do SIES (2010-2012).

A maior dificuldade dos EES de assentamentos agrários (Tabela 1) dá-se no capital de giro (58,38\%), esboçando a dificuldade de obter capital necessário para financiar a continuidade das operações da empresa, como recursos para financiamento aos clientes (nas vendas a prazo), recursos para manter estoques e recursos para pagamento aos fornecedores (compras de matéria-prima ou mercadorias de revenda), pagamento de impostos, salários e demais custos e despesas operacionais (FABRINI, 2001; MEDEIROS; LEITE, 2004; STEDILE, 2005). Além disso, há dificul- 
dade ou custo elevado de transporte $(50,84 \%)$ somado a precariedade das estradas para escoamento da produção (43,02\%).

\subsubsection{Comercialização ou Organização da Comercialização}

$\mathrm{Na}$ atividade econômica comercialização ou organização da comercialização é possível observar que dentre 1.033 empreendimentos com a característica de assentamento de reforma agrária, 172 apontaram realizar essa atividade, representando $16,65 \%$ dos respondentes. Sobre a forma de organização da comercialização desses EES fica evidente que as feiras e centrais de comercialização são as principais formas de organização da comercialização, cada uma representando 41,28\% das respostas, além de outras formas utilizadas pelos assentamentos, no caso lojas ou espaços fixos de venda, com 36,63\% das respostas e o comércio eletrônico representando apenas $0,58 \%$ das respostas como principal forma de organização da comercialização. Vale também ressaltar que os empreendimentos poderiam assinalar mais de uma alternativa nessa questão (AZEVEDO; FAULIN, 2009).

As formas de comercialização são expostas na Tabela 2.

Tabela 2. Forma de comercialização

\begin{tabular}{lcc}
\hline Forma de comercialização & Frequência & $\%$ \\
\hline Venda a revendedores/atacadistas como forma de comercialização & 99 & $57,56 \%$ \\
Venda direta ao consumidor final como forma de comercialização & 87 & $50,58 \%$ \\
Venda para empresas privadas de produção como forma de comercia- & 74 & $43,02 \%$ \\
lização & 36 & $20,93 \%$ \\
Venda a órgão governamental como forma de comercialização & 7 & $4,07 \%$ \\
Venda a outros EES como forma de comercialização & 2 & $1,16 \%$ \\
Troca com outros EES como forma de comercialização & 2 & $1,16 \%$ \\
\hline Outros
\end{tabular}

Fonte: Elaborado pelos autores com base nos dados do SIES (2010-2012).

Outra questão levantada pela base de dados do SIES é em relação à forma de comercialização adotada pelos assentamentos e a Tabela 2 confirma que a principal forma é venda a revendedores ou atacadistas o que representa 57,56\% das respos- 
tas, ressaltando também que os empreendimentos poderiam assinalar mais de uma forma de comercialização. Assim, outra forma bastante utilizada é a venda direta ao consumidor; representando 50,58\% das respostas, a tabela nos mostra também os números e porcentagem de respostas sobre as formas de comercialização, como venda às empresas privadas, órgão governamental, venda ou troca com outro empreendimento econômico solidário e, também, outras formas de comercialização (AZEVEDO; FAULIN, 2009).

A Tabela 3, a seguir, evidencia dados sobre o mercado dos EES.

Tabela 3. Mercado

\begin{tabular}{|c|c|c|}
\hline Mercado & Frequência & $\%$ \\
\hline $\begin{array}{l}\text { Venda ou troca de produtos realiza-se no Mercado/comércio local ou co- } \\
\text { munitário }\end{array}$ & 93 & $54,07 \%$ \\
\hline $\begin{array}{l}\text { Venda ou troca de produtos realiza-se no Mercado/comércio territorial ou } \\
\text { microrregional }\end{array}$ & 86 & $50,00 \%$ \\
\hline Venda ou troca de produtos realiza-se no Mercado/comércio municipal & 78 & $45,35 \%$ \\
\hline Venda ou troca de produtos realiza-se no Mercado/comércio estadual & 22 & $12,79 \%$ \\
\hline Venda ou troca de produtos realiza-se no Mercado/comércio nacional & 7 & $4,07 \%$ \\
\hline Venda ou troca de produtos realiza-se no Mercado/comércio externo & 2 & $1,16 \%$ \\
\hline
\end{tabular}

Fonte: Elaborado pelos autores com base nos dados do SIES (2010-2012).

A Tabela 3 ressalta que o principal mercado dos produtos advindos dos assentamentos é o comércio local ou comunitário. Destaca-se também o comércio territorial ou microrregional, em que esses dois mercados representam respectivamente $54,07 \%$ e $50 \%$ das respostas. A venda dos produtos no comércio municipal merece destaque, representando $45,35 \%$ das respostas. Como na tabela anterior, os assentamentos poderiam responder mais de uma variável.

A pesquisa abordou se os assentamentos de reforma agrária tinham dificuldades em relação à comercialização de seus produtos. Identificou-se que entre os 172 empreendimentos, 74 empreendimentos destacaram ter alguma dificuldade, representando 43,02\% dos assentamentos pesquisados (Tabela 4). 
Tabela 4. Dificuldades na comercialização dos produtos

\begin{tabular}{|c|c|c|}
\hline Dificuldades & Frequência & $\%$ \\
\hline Dificuldade ou custo elevado de transporte & 49 & $66,22 \%$ \\
\hline Falta de capital de giro & 48 & $64,86 \%$ \\
\hline Precariedade das estradas para escoamento da produção & 43 & $58,11 \%$ \\
\hline A concorrência, os atravessadores, existência de monopólios & 30 & $40,54 \%$ \\
\hline $\begin{array}{l}\text { Estrutura para comercialização (local, espaço, equipamentos etc.) ina- } \\
\text { dequada }\end{array}$ & 31 & $41,89 \%$ \\
\hline Dificuldade em manter a regularidade do fornecimento & 24 & $32,43 \%$ \\
\hline Falta de registro sanitário ou alvará & 23 & $31,08 \%$ \\
\hline Falta de registro legal para a comercialização (emitir nota fiscal etc.) & 22 & $29,73 \%$ \\
\hline Os preços praticados são inadequados & 20 & $27,03 \%$ \\
\hline Os clientes exigem um prazo para o pagamento & 14 & $18,92 \%$ \\
\hline Os compradores só compram em grande quantidade & 12 & $16,22 \%$ \\
\hline $\begin{array}{l}\text { O empreendimento tentou, mas não conseguiu encontrar quantidade } \\
\text { suficiente de clientes }\end{array}$ & 9 & $12,16 \%$ \\
\hline Não há sócios disponíveis para cuidar da comercialização & 8 & $10,81 \%$ \\
\hline O empreendimento já sofreu muitos calotes e não sabe como evitar & 7 & $9,46 \%$ \\
\hline $\begin{array}{l}\text { Ninguém do empreendimento sabe como se faz uma venda (argumen- } \\
\text { tação, negociação etc.) }\end{array}$ & 6 & $8,11 \%$ \\
\hline Os produtos não são conhecidos & 3 & $4,05 \%$ \\
\hline Outra dificuldade & 9 & $12,16 \%$ \\
\hline
\end{tabular}

Fonte: Elaborado pelos autores com base nos dados do SIES (2010-2012).

As principais dificuldades encontradas dizem respeito às dificuldades ou custo elevado de transporte, falta de capital de giro e precariedade das estradas para escoamento da produção, em que representam respectivamente 66,22\%, 64,86\% e $58,11 \%$ das respostas (Tabela 4). Os empreendimentos poderiam assinalar mais de uma dificuldade; entre as dificuldades relacionadas, $12,16 \%$ assinalaram ter outras dificuldades diferentes das disponíveis para resposta. 


\section{CONSIDERAÇÕES FINAIS}

Esse artigo analisou a comercialização em assentamentos da reforma agrária considerando como características da comercialização: redes, destino dos produtos, tipo de venda, mercado comprador, espaço de comercialização, forma de organização da comercialização, produtos comercializados, forma de comercialização, mercado e dificuldades na comercialização dos produtos. Identificou-se, por meio dos dados do SIES, que a maior parte dos EES com categoria social assentamentos da reforma agrária está localizada na região Nordeste do Brasil. A principal atividade econômica, em um panorama nacional, é a produção ou produção e comercialização, corroborando a necessidade de autoconsumo da própria comunidade e geração de renda e excedente.

Embora a formação de redes de colaboração solidária seja interessante para o desenvolvimento dos EES, grande parte dos assentamentos agrários não participa de redes de comercialização, ilustrando a resistência e necessidade de implementação desse arranjo organizacional no contexto dos assentamentos de reforma agrária. Em contrapartida, os níveis mais baixos de participação em redes ocorrem especialmente em rede de comercialização e rede de produção, assemelhando-se diretamente com a maior porcentagem referente à característica de atividade econômica.

Além disso, a principal destinação dos produtos é a venda e o autoconsumo. Os principais mercados consumidores são o mercado/comércio municipal e o mercado/comércio local ou comunitário. Ambas variáveis se alinham à ideia de fortalecimento do próprio grupo de assentados, inserção de produtos no contexto do agronegócio e promoção de bem-estar dos trabalhadores, reforçando os próprios valores e desígnios da reforma agrária.

Para pesquisas futuras, como sugestão, seria interessante analisar a existência de redes de comercialização entre os EES e, dessa maneira, analisar se fomentam efetivamente o crescimento em cadeias produtivas e redes solidárias.

\section{REFERÊNCIAS}

AZEVEDO, P. F.; FAULIN, E. J. Comercialização na agricultura familiar. In: SOUZA FILHO, H. M.; BATALHA, M. O. Gestão Integrada da Agricultura Familiar. São Carlos: EdUFSCar, 2009. 
BATALHA, M. O. (Org.) Gestão Agroindustrial. São Paulo: Atlas, 2001.

BENINI, E. A.; BENINI, E. G. Reforma agrária no contexto da economia solidária. Revista Nera, v. 11, n. 13, p. 6-15, jul./dez. 2008.

BRASIL. Lei $\mathrm{n}^{\mathrm{O}}$ 4.504, de 30 de novembro de 1964. Dispõe sobre o Estatuto da Terra, e dá outras providências. Disponível em: < http://www.planalto.gov.br/ccivil_03/leis/14504.htm>. Acesso em: 30 set. 2016.

CASTRO, C. C. O Processo de Coordenação de Cadeias Agroalimentares. In: Anais do III Congresso Internacional de Economia e Gestão de Negócios (networks) Agroalimentares: FEA- USP, Campus de Ribeiro Preto, 2001.

CHING, H. Y. Gestão de Estoque na Cadeia Logística Integrada: Supply Chain. São Paulo: Atlas, 1999.

COLLIS, J.; HUSSEY, R. Pesquisa em administração: um guia prático para alunos de graduação e pós-graduação. 2. ed. Porto Alegre: Bookman, 2005.

COOPER, D. R.; SCHINDLER, P. S. Métodos de pesquisa em administração. 10a ed. Porto Alegre: Bookman, 2011.

COSTA, B. A. L.; AMORIM JUNIOR, P. C. G.; SILVA, M. G. As cooperativas de agricultura familiar e o Mercado de compras governamentais em Minas Gerais. RESR, Piracicaba, v. 53, p. 109-126, 2015.

DAVIS, J. H.; GOLDBERG, R. A Concept of Agribusiness. Boston: Harvard University, 1957.

ESTERCI, N.; MEDEIROS, L. S.; FRANCO, M. P.; LEITE, S. Assentamentos Rurais: um convite ao debate. Revista da Associação Brasileira de Reforma Agrária - ABRA, São Paulo, v. 22, n. 3, set./dez. 1992.

FABRINI, J. E. Assentamentos de Trabalhadores Sem-Terra: experiência de lutas no Paraná. Marechal Cândido Rondon: LGeo, 2001.

GAIGER, L. I. G. A economia solidária diante do modo de produção capitalista. Caderno CRH, Salvador, n. 39, p. 181-211, jul./dez. 2003.

GODOY, A. S. Introdução à pesquisa qualitativa e suas possibilidades. Revista de Administração de Empresas, v. 35, n. 3, p. 20-29, 1995. 
GOLBERG, R. A. Agribusiness coordination: a systems approach to the Wheat, soybean and Florida orange economies. Division of Research. Graduate School of Business Administration. Harvard University, Boston, 1968.

INCRA. Instituto Nacional de Colonização e Reforma Agrária. Famílias assentadas. Disponível em: < http://www.incra.gov.br/tree/info/file/9608> . Acesso em: 02 nov. 2016.

INCRA. Reforma Agrária. Programa Reforma Agrária, 2017. Disponível em: <www. incra.gov.br/reformaagraria > . Acesso em: 18 out. 2017.

MARTINS, H. H. T. S. Metodologia qualitativa de pesquisa. Educação e Pesquisa, v. 30, n. 2, p. 289-300, 2004.

MEDEIROS, L. S.; LEITE, S. Assentamentos rurais e mudanças locais: uma introdução ao debate. In: MEDEIROS, L. S.; LEITE, S. Assentamentos rurais: mudança social e dinâmica regional. Rio de Janeiro: Muad, 2004.

MENDES, E. A. Como organizar redes solidárias. Euclides André Mande (org.). Rio de Janeiro: DP\&A, Fase, IFiL, 2003.

MONTIGAUD, J.-C. L'analyse des filières agro-alimentaires: méthodes et premiers résultats. Economies et Sociétés, Série AG, n. 21, 1992.

SILVA, M. G.; DIAS, M. M.; AMORIM JUNIOR, P. C. G. Mudanças organizacionais em empreendimento de agricultura familiar a partir do acesso ao Programa Nacional de Alimentação Escolar. RESR, Piracicaba, v. 53, p. 289-340, 2015.

SINGER, P. I. A recente ressurreição da economia solidária no Brasil. In: SANTOS, B. S. (Org.). Produzir para viver: os caminhos da produção não capitalista. 2. ed. Rio de Janeiro: Civilização Brasileira, 2002.

STEDILE, J. P. A questão da reforma agrária no Brasil: programas de reforma agrária 1946-2003. São Paulo: Expressão Popular, 2005.

Recebido em: 04/11/2016 Aceito em: 05/11/2017 